\title{
Exploring Angrite Meteorites with Microanalysis: A Broad Spectrum Approach to Constraining Petrogenesis
}

Steven J. Singletary ${ }^{1}$, Anthony B. Love ${ }^{2}$, Shangshang $\mathrm{Mu}^{3}$, Shichun Huang ${ }^{4}$, John Sinclair ${ }^{5}$ and Don Cline ${ }^{5}$.

1. Science Department, Robeson Community College, Lumberton, NC, USA

2. Department of Geological and Environmental Sciences, Appalachian State University, Boone, NC, USA

3. SENCR-MIC, Fayetteville State University, Fayetteville, NC, USA

${ }^{4}$ Department of Geosciences, University of Nevada-Las Vegas, Las Vegas, NV, USA

${ }^{5}$ Pisgah Astronomical Research Institute, Rossman, NC, USA

The Angrite meteorite group is comprised of a diverse set of ancient and enigmatic achondrites. Members of the group have been dated to $4563.36 \pm 0.34 \mathrm{Ga}$ [1], making them almost as old as the solar system itself. Angrites fall into two distinct groups easily distinguished by textures indicating cooling regimes from shallow dike and lava flow emplacement (referred to hereafter as volcanic angrites) to deep seated plutonism (referred to hereafter as plutonic angrites) [2]. Angrite ages and textures indicate they were formed on a planetary sized body when many short lived isotopes were still present (i.e. $\left.{ }^{26} \mathrm{Al}\right)$ and therefore provide important clues to the earliest stages of planetary melting and differentiation. Consequently, candidates for the Angrite parent body (APB) range from Mercury to large asteroids disrupted early in solar system history [3].

Major mineral phases present in angrites include Fe-Al-Ti rich augite, anorthite, Mg-rich olivine, $\mathrm{Ca}-\mathrm{Fe}$ rich olivine, kirschsteinite and various phosphates, oxides, sulfides and Fe-Ni metal [4,5]. All samples display a textural equilibrium even though the major phases are not normally found in chemical equilibrium [5]. Several members of the angrite group, notably D'Orbigny (a volcanic angrite), display voids within the stones that contain druzy crystals of honey-colored augite [6]. The source characteristics of the angrite parent liquids (composition, temperature, pressure, etc.) remain unknown $[7,8]$.

Here we present initial results of a study to investigate volcanic and plutonic angrites in order to place constraints on their petrogenesis and the nature of the angrite parent body. Data, including BSE images, EDS maps, CL spectrum maps and spot WDS analyses were collected using the JEOL JXA-8530F Hyperprobe located at Fayetteville State University. Two samples, one volcanic (D’Orbigny) and one plutonic (NWA 6291), were analyzed in this study. NWA 6291 was purchased in Morocco in 2010 and has a total mass of 250 grams; D’Orbigny was found near Buenos Aires, Argentina in 1979 and has a total mass of $16.55 \mathrm{~kg}$.

Olivine is present as the major phase in many angrites [5]. Angritic olivine is characterized by several core to rim variations in the major elements, most notably an increase in Calcium- up to 10 mol \% [9]. These represent the highest Calcium contents of any known natural olivine. Cathodoluminescence imaging using the xCLent system revealed the presence of structures and patterns that are not readily visible in either BSE or EDS imaging (see Figure 1 and Figure 2). These features reveal important clues about the evolution of these samples on their parent body. 
Based on zonations revealed by the CL imaging (such as that shown in Figure 2) angritic olivine grains are targeted with in-situ, high spatial resolution analyses of major element abundances in transects across the now apparent transitional areas. These analyses will be used to guide measurements of $\mathrm{Fe}, \mathrm{Mg}$ and $\mathrm{Ca}$ isotopic compositions to constrain crystallization conditions and kinematics. The major element abundances and isotopic compositions will be used to evaluate possible equilibration temperatures and cooling rates of the different angrite meteorites, following the new modeling methods developed by [10], and such results will place important constraints on the nature of the APB.

\section{References:}

[1] G Brennecka et al, Science, 327, 2010.

[2] G McKay et al, Geochimica et Cosmochimica Acta, 58, 1994.

[3] A Irving et al, Lunar Planetary Science XLIV, 2013.

[4] G Kurat et al, Geochimica et Cosmochimica Acta, 68, 2004.

[5] M Varela et al, Lunar Planetary Science XLVI, 2015.

[6] D Mittlefehldt et al in "Planetary Materials", ed. J Papike, (Reviews in Mineralogy, Washington, DC) p 4-1 - 4-195.

[7] J Longhi, Geochimica et Cosmochimica Acta, 63, 1999.

[8] M Varela et al, Geochimica et Cosmochimica Acta, 217, 2017.

[9] D Mittlefehldt et al, Meteoritics and Planetary Sciences, 37, 2002.

[10] X Zhao et al, Geochimica et Cosmochimica Acta, 208, 2017.

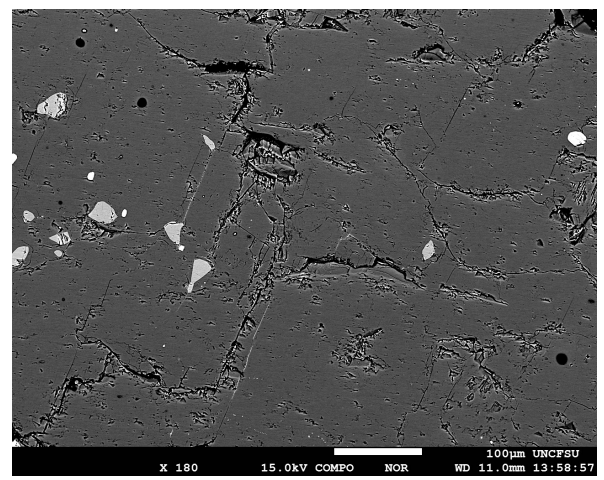

Figure 1. Backscattered Electron Image of plutonic angrite NWA 6291. The field of view is the same as that shown in Figure 2.

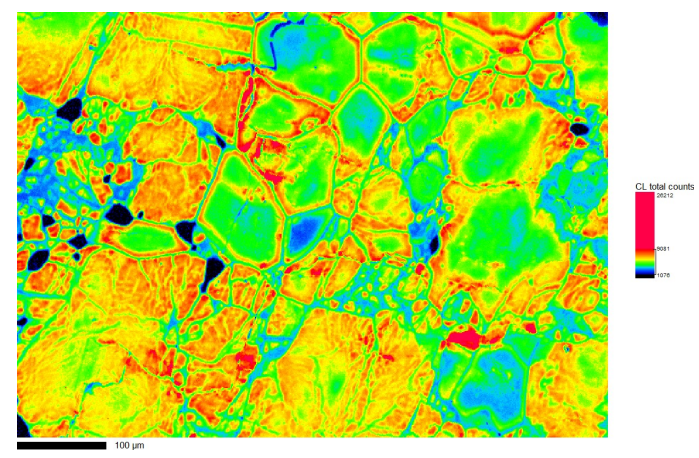

Figure 2. CL spectrum map collected from the same area as that shown in Figure 1 using the $\mathrm{xCLent}$ spectrograph installed on the FSU JEOL JXA 8530F Hyperprobe. Zonations and crystal grain features are revealed that are not visible in the BSE image. 